\title{
Does ACPA-negative RA consist of subgroups related to sustained DMARD- free remission and serological markers at disease presentation? Comment on article by Boeters DM et al.
}

\author{
Alfonse T. Masi ${ }^{{ }^{*}}$ (I) and Roy Fleischmann ${ }^{2}$
}

Keywords: Rheumatoid arthritis, Anti-citrullinated protein antibody (ACPA), Multi-biomarker disease activity (MBDA) score, Remission

Letter to the Editor

We read with interest the article by Boeters DM et al. [1]. We would like to clarify the significant findings and suggest further research needed to validate the novel conclusion. In ACPA-negative patients, 1 sustained DMARD-free remission (SDFR) occurred over 5 years follow-up in $17(6 \%)$ with baseline low $(<30)$ MBDA score vs approximately $50 \%$ remissions in both moderate (30-44) and high (>44) MBDA score patients ([1], Fig. 1). All ACPA-positive RA patients had low percentages of SDFR and no difference was found by baseline MBDA score category [1]. Percentages of 3 MBDA categories did not differ $(p=0.470)$ between the ACPA-positive and ACPA-negative groups [1].

SDFR was recently reported by ACPA-negative vs ACPApositive patients in the total Leiden early arthritis cohort (1993-2016; $n=1296)$ [2], from which the Boeters et al. study [1] was the most recent inclusion subgroup (20112016). In the total inclusion period (1993-2011), SDFR occurred between 5 and 15\% in ACPA-positive RA vs 40 to $50 \%$ in the ACPA-negative RA [2], as in Boeters et al. [1].

Unexpectedly, in multivariate analyses ([1], Table 2), the 95 ACPA-negative RA patients with high ( $>44)$ baseline scores had greater DMARD-free remission than the 17 reference patients with low $(<30)$ MBDA scores $(p=$ 0.041). If MBDA were truly a marker of disease activity, one might expect low rather than high MBDA to predict

\footnotetext{
* Correspondence: amasi@uic.edu

${ }^{1}$ Department of Medicine, University of Illinois College of Medicine at Peoria, One Illini Drive, Peoria, IL, USA

Full list of author information is available at the end of the article
}

SDFR. Alternatively, if ACPA-negative RA does consist of subgroups [1], its documentation will require further serological study in separate cohorts $[2,3]$ or search for genetic markers [3]. Confounding variables should be excluded, possibly clinical features related to age at onset, which was found to be a significant $(p=0.036)$ predictor of SDFR ([1], Table 2) and other disease variables not studied. Is it conceivable that this anomaly [1] is due to chance occurrence in a small sample size study leading to an incorrect conclusion, especially when borderline $(p=$ 0.041) statistical correlation is found [1]?

A critical review of the value of multibiomarker disease activity score to predict remission in RA was recently published [4]. The challenging question is whether or not baseline MBDA (or serological markers) are being overinterpreted or overstated with respect to outcomes (or disease subgroups) was critically analyzed [4].

\section{Acknowledgements}

No acknowledgements or conflict of interest.

\section{Authors' contributions \\ Both authors contributed to interpretation of published and comments in Letter. Both authors read and approved the final manuscript.}

\section{Funding}

No funding contributed to the statements in the letter.

\section{Availability of data and materials}

Data are in published article and reference citations.

\section{Ethics approval and consent to participate}

Letter refers to published article without new subjects. 


\section{Consent for publication}

Both authors agree to publication.

\section{Competing interests}

The authors declare that they have no competing interests.

\section{Author details}

'Department of Medicine, University of Illinois College of Medicine at Peoria, One Illini Drive, Peoria, IL, USA. ${ }^{2}$ Co-Medical Director Metroplex Clinical Research Center, University of Texas Southwestern Medical Center, 8144 Walnut Hill Lane Suite 810, Dallas, TX 75231, USA.

Received: 27 November 2019 Accepted: 21 January 2020

Published online: 31 January 2020

\section{References}

1. Boeters DM, Burgers LE, Sasso EH, Huizinga TWJ, van der Helm-van Mil AHM. ACPA-negative RA consists of subgroups: patients with high likelihood of achieving sustained DMARD-free remission can be identified by serological markers at disease presentation. Arthritis Res Ther. 2019;21:1-9.

2. Matthijssen XM, Niemantsverdriet E, Huizinga TW, van der Helm-van Mil AHM. ACPA-positive patients benefited more than ACPA-negative patients; 25 year results of a longitudinal cohort study. Presentation 2871 at the 2019 American College of Rheumatology Meeting, Atlanta GA (pps 5098-5100 in <https:// acrabstracts.org/wp-content/uploads/2019/10/2019-Abstract-Supplement.pdf>).

3. Hedström AK, Rönnelid J, Klareskog L, Alfredsson L. Complex relationships of smoking, HLA-DRB1 genes, and serologic profiles in patients with early rheumatoid arthritis: update from a Swedish population-based case-control study. Arthritis Rheumatol. 2019;71:1504-11.

4. Fleischmann R. Value of the multibiomarker of disease activity score to predict remission in RA: what does the evidence show? J Rheumatol. 2019:46:443-6.

\section{Publisher's Note}

Springer Nature remains neutral with regard to jurisdictional claims in published maps and institutional affiliations. 